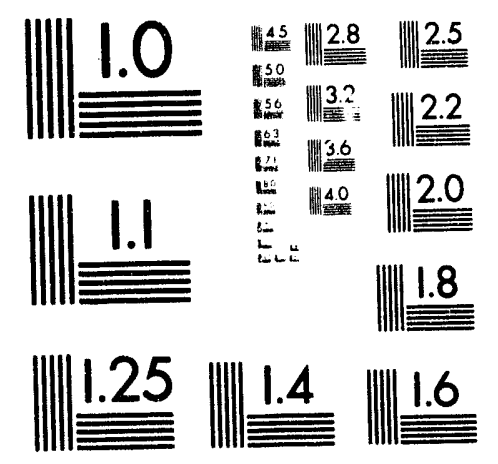



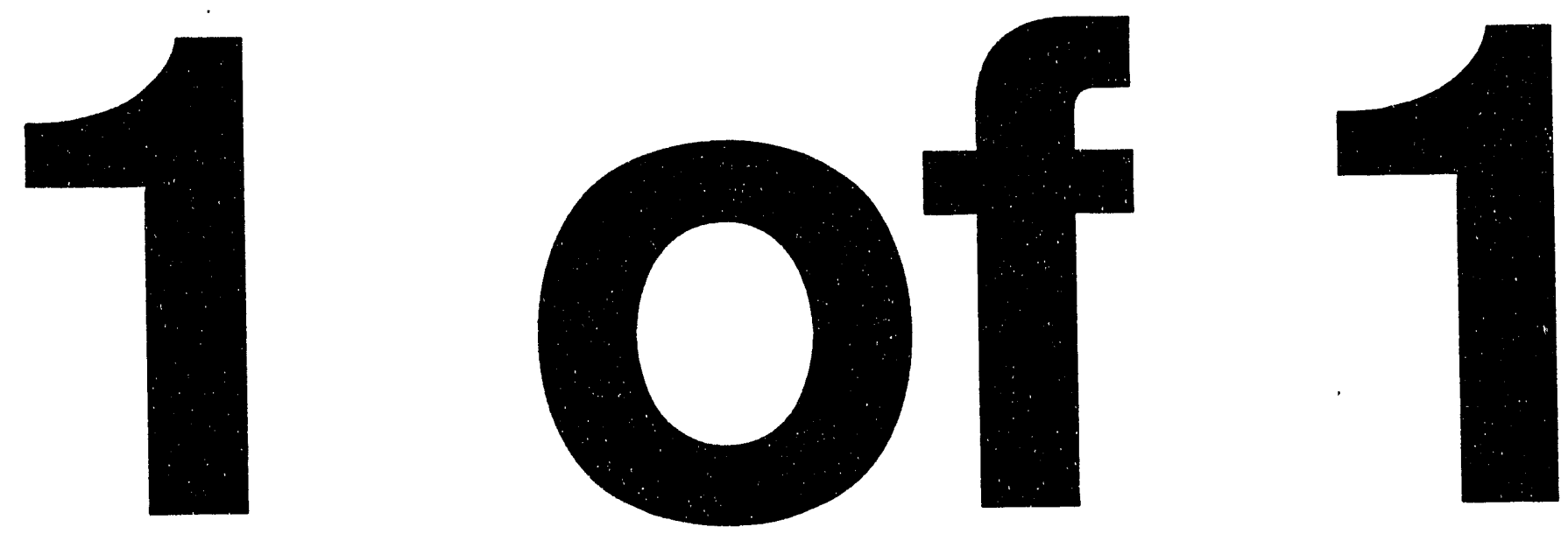


\title{
Suppression of Fine Ash Formation in Pulverized Coal Flames
}

DOE Grant No. DE-FG22-92PC92548

Period of Performance: September 30, 1992 to January 31, 1995

Quarterly Technical Progress Report No. 3

Period Covered by Report: April 1, 1993 to June 30, 1993

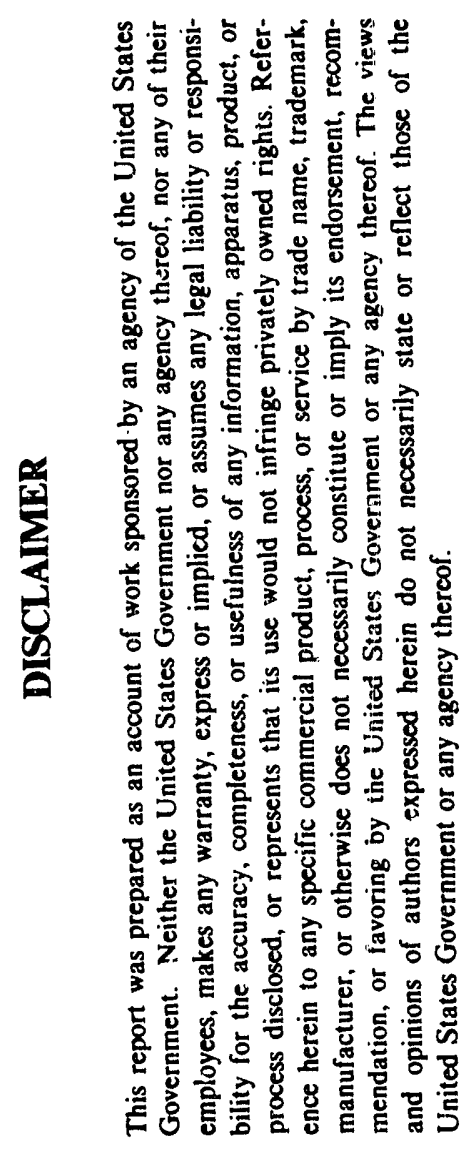

\author{
Prepared by: \\ JOHN C. KRAMLICH \\ DAVID A. HOFFMAN \\ ERIC K. BUTCHER \\ Department of Mechanical Engineering, FU-IO \\ University of Washington \\ Seattle, Washington 98195 \\ Prepared for: \\ DOCUMENT CONTROL CENTER \\ U. S. Department of Energy \\ Pittsburgh Energy Technology Center \\ P. O. Box 10940, MS $921-118$ \\ Pittsburgh, Pennsylvania 15236-0940
}

Date Submitted: July 23, 1993

"U.S./DOE Patent Clearance is not required prior to the publication of this document." 


\section{Introduction}

One of the major obstacles to the economical use of coal is managing the behavior of its mineral matter. Ash size and composition are of critical importance for a variety of reasons. Fly ash size and emissivity affect radiant furnace heat transfer. 1 Heat transfer is also affected by the tendency of ash to adhere to heat transfer surfaces, 2 and the properties of these deposits. 3

Removal of ash from flue gas by electrostatic precipitators is influenced by both particle size and particle resistivity. ${ }^{4}$ The efficiency of fabric filter-based cleaning devices is also influenced by ash size. 5 Both types of devices have reduced collection efficiencies for smaller-sized particles, which corresponds to the size most efficiently retained in the alveolar region of the human lung. ${ }^{6}$ This special concern for finer sized particles has led to PM10 regulations in the last several years (PM10: particles of diameter less than $10 \mu \mathrm{m}$ ).

Laboratory work and studies of full-scale coal-fired boilers have identified two general mechanisms for ash production. The vast majority of the ash is formed from mineral matter that coalesces as the char burns, yielding particles that are normally larger than $0.5 \mu \mathrm{m}$. Flagen and Friedlander ${ }^{7}$ proposed a simple model for this residual ash, called the breakup model. In this model, each particle is assumed to yield its mineral matter as a certain specified number of ash particles (usually in the range of 1-5). This latter value is termed the "breakup number." In this way, a known pulverized coal size distribution can be transformed into a projected ash size distribution. The presumed mechanism is that each char particle fragments during combustion, carrying mineral matter with it. The major assumptions used in the model include: (1) all coal particles contain the same percentage of mineral matter, independently of size, (2) all coal particles break into exactly the same number of char particles during combustion, (3) each char particle contains the same amount of mineral matter as the other char particles, and (4) no further fragmentation occurs, which means that each offspring char particle yields its mineral matter as a single ash particle. The breakup number has been identified in recent work as being influenced by the breakup of the char duri.g burnout, from shedding at the burning char surface, ${ }^{8}$ and from the fragmentation of discrete included and excluded minerals. 9.10 Recent experimental work 11 and elegant site percolation modeling 12 indicate that char macroporosity is the single most important factor governing char breakup and residual ash size. Despite the severity of the assumptions, the basic breakup model has proven to be a useful engineering and interpretative tool. ${ }^{13}$

The second major mechanism is the generation of a submicron aerosol through a vaporization/condensation mechanism. When the ash size distribution is plotted in terms of number density, the submicron mode generally peaks at about $0.1 \mu \mathrm{m} .{ }^{4}$ When plotted in terms of mass, this mode is sometimes distinct from the residual ash mode, 13 and sometimes merged into it. 14 During diffusion-limited char combustion, the interior of the particle becomes hot and fuelrich. The non-volatile oxides (e.g., $\mathrm{Al}_{2} \mathrm{O}_{3}, \mathrm{SiO}_{2}, \mathrm{MgO}, \mathrm{CaO}, \mathrm{Fe}_{2} \mathrm{O}_{3}$ ) can be reduced to more volatile suboxides and elements, and partially vaporized.15-17 These reoxidize while passing through the boundary layer surrounding the char particle, thus becoming so highly supersaturated that rapid homogeneous nucleation occurs. This high nuclei concentration in the boundary layer promotes more extensive coagulation than would occur if the nuclei were uniformly distributed across the flow field. It The vaporization can be accelerated by the overshoot of the char temperature beyond the local gas temperature. 19

Although these particles represent a relatively small fraction of the mass, they can present a large fraction of the surface area. Thus, they are a preferred site for the condensation of the more volatile oxides later in the furnace. This leads to a layering effect in which the refractory oxides are concentrated at the particle core and the more volatile oxides reside at the surface. 20 This also explains the enrichment of the aerosol by volatile oxides that has been noted in samples from practical furnaces. 21 These volatile metal oxides include the majority of the toxic metal contaminants, e.g., mercury, arsenic, selenium and nickel. Risk assessment studies suggest that toxic metal emissions represent a significant portion of the health risk associated with combustion 
systems. 22

Previous work has shown that pulverized bituminous coals that were treated by coal cleaning (via froth flotation) or aerodynamic sizing exhibited altered aerosol emission

characteristics. Specifically, the emissions of aerosol for the cleaned and sized coals increased by as much as one order of magnitude. At least three mechanisms have been proposed to account for this behavior.

\section{Objectives}

The goals of the present program are to:

1. Perform measurements on carefully characterized coals to identify the means by which the coal treatment increases aerosol yields.

2. Investigate means by which coal cleaning can be done in a way that will not increase aerosol yields.

3. Identify whether this mechanism can be used to reduce aerosol yields from systems burning straight coal.

\section{Progress - Mechanistic Interpretation}

Additional modeling and interpretation work have been performed on the existing data base. This has focused on fine residual aerosol particles in the range of $0.5-5 \mu \mathrm{m}$. This work was submitted to Fuel Processing Technology, and a revised version of the paper has been accepted for publication. This work is reproduced in the appendix of this report.

\section{Progress - Furnace Modification}

The bulk of the work during the present quarter has been associated with furnace modification. The following section provides a brief overview of the furnace design. This is followed by a discussion of the specific progress during this quarter.

\section{Furnace Design Goals}

The fundamental goal of the furnace design is to provide a sufficient temperature and residence time to ensure complete coal burnout. Based on past experience with similar types of experimental furnaces, a main burner firing rate of $16.1 \mathrm{~kW}(55,000 \mathrm{Btu} / \mathrm{hr})$ was chosen. Additionally, in order to ensure burnout, the furnace stoichiometry was set to provide $7 \%$ free oxygen after combustion.

Figure 1 shows a sketch of the furnace as it will look after installation. The unit will have natural gas, air, and cooling water brought into the appropriate accessories. The main burner sits atop the furnace, and the four back-fired burners, forming two pairs of heating channels, can be seen in the middle section of the furnace. Figure 2 is a cross-section of the furnace showing the multiple refractory layer design. The inner tunnel diameter is $20.3 \mathrm{~cm}$ (8 inches) and the overall outside diameter is $91.5 \mathrm{~cm}$ ( 36 inches). This requires $35.5 \mathrm{~cm}$ (14 inches) thickness of insulating material. In spite of this relatively thick layer of insulation, heat transfer calculations show that the combustion gas temperature may drop by up to $200^{\circ} \mathrm{C}$ as the gases move down the tunnel and reach the exhaust piping. Thus, the two pairs of backfire burners were included. These are designed to be operated independently to provide whatever inner tunnel temperature profile is desired. Each of the four back-fired burners can operate at up to $16.1 \mathrm{~kW}$, but will likely run at a lower firing rate. The maximum flame temperature will be $1600^{\circ} \mathrm{C}$, and this can be varied by controlling the burner air flow rate. 


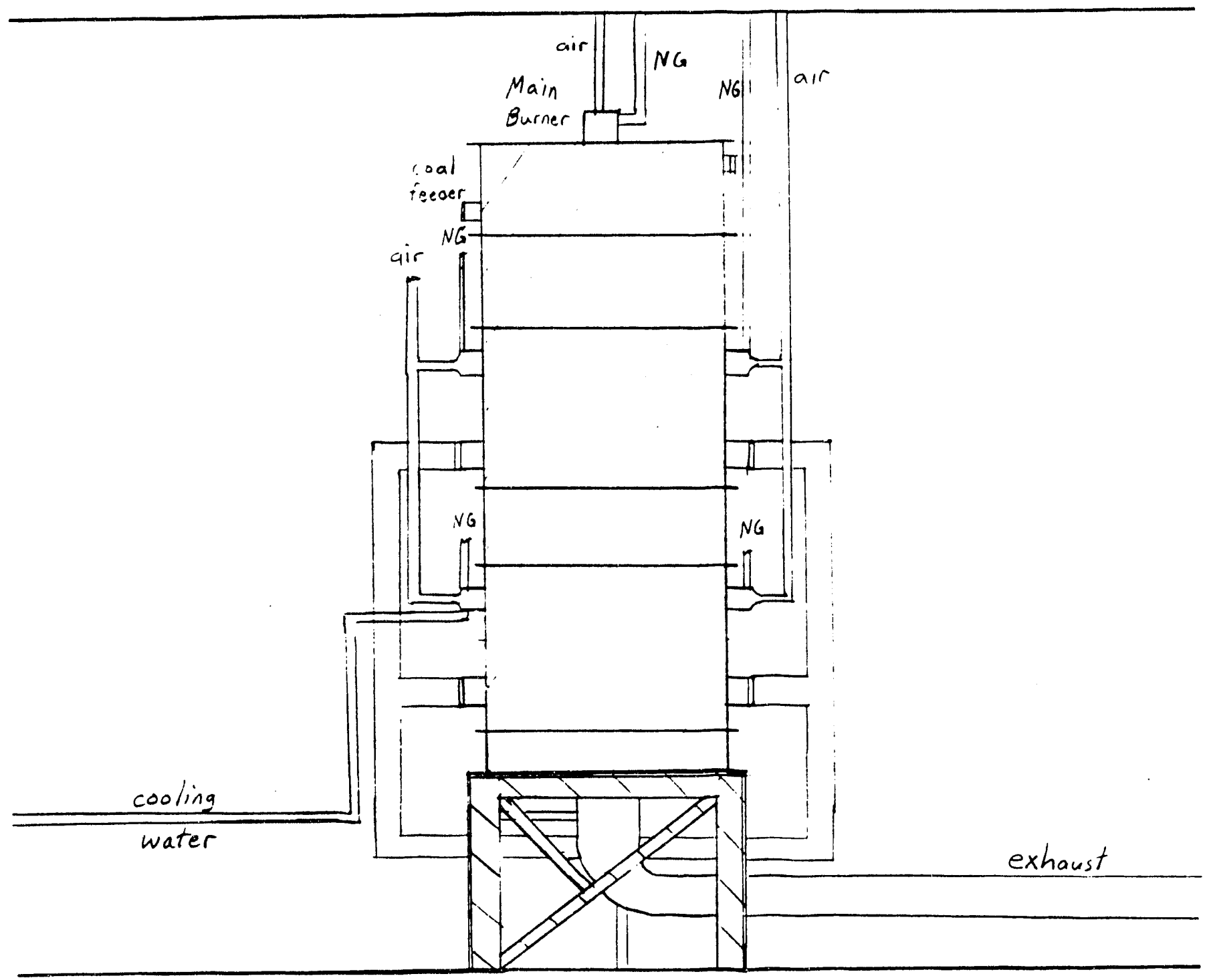

Figure 1. Cverview of the tunnel furnace layout. 


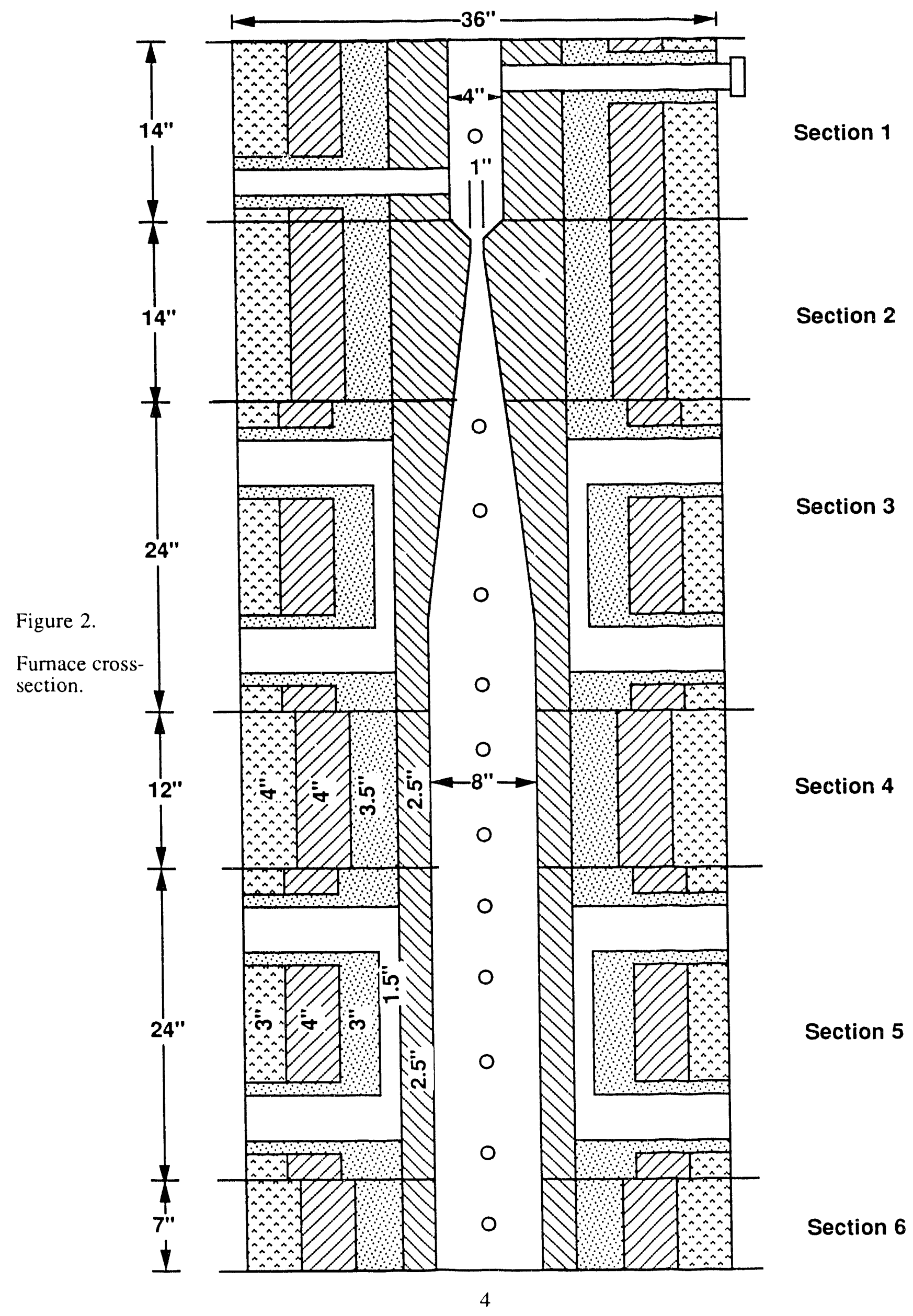


Furnace Construction

During this quarter, the following items were completed.

- All casting was completed.

- The furnace was stacked and bolted, and is now ready for curing

- The reactant flow systems have been received and are now being installed.

- The safety control systern has been specified and ordered.

- Physical plant completed modifications to the reactor bay to accommodate the reactor.

- Designs for the exhaust system have been completed and are in the physical plant shop.

- The reactor shells for each section, including ports and flanges were completed.

\section{References}

1. Gupta, R. J. Radiative Transfer Due to Fly Ash in Coal Fired Firnaces, Ph.D. Dissertation 1983, University of Newcastle.

2. Walsh, P. M., Sayre, A. N., Loehden, D. O., Monroe, L. S., Beér, J. M., and Sarofim, A. F. Prog. Energy Combust. Sci. 1990, 16, 327.

3. Field, M. A., Gill, D. W., Morgan, B. B., and Hawksley, P. G. W. Combustion of Pulverized Coal. 1967. The British Coal Utilization Research Association.

4. McCain, J. D., Gooch J. P., and Smith, W. B. Journal of the Air Pollution Control Association 1975, 25, 117.

5. Friedlander, S. K. Smoke, Dust and Haze 1977, Wiley.

6. Morrow, P. E. Amer. Ind. Hyg. Assoc. J. 1964, 25, 213.

7. Flagen, R. C., and Friedlander, S. K. Recent Developments in Aerosol Science. (D. T. Shaw, Ed.) 1978, Wiley, Chapter 2.

8. Helble, J. J., and Sarofim, A. F. Combust. Flame 1989, 76, 183.

9. Baxter, L. L. Prog. Energy Combust. Sci. 1990, 16, 261.

10. Srinivasachar, S., Heible, J. J., and Boni, A. A. Prog. Energy Combust. Sci. 1990, 16, 281.

11 Helble, J. J., and Sarofim, A. F. Combust. Flame 1989, 76, 183.

12. Kang, S., Helble J. J., Sarofim A. F., and Beér, J. M. Twenty-Second Symposium (International) on Combustion 1988, The Combustion Institute, p. 231.

13. Flagen, R. C. Seventeenth Symposium (International) on Combustion 1979, The Combustion Institute, p. 97.

14. Linak, W. P., and Peterson, T. W. Aerosol Sci. Technol. 1984, 3, 77.

15. Neville, M., Quann. R. J., Haynes. B. S., and Sarofïn, A. F. Eighteenth Symposium (International) on Combustion. 19)81, The Combustion Institute, p. 1267.

16. Senior, C. L., and Flagen, R. C. Aerosol. Sci. Technol. 1982, 1, 371.

17. Quann, R. J., and Sarofim, A. F. Nineteenth Symposium (International) on Combustion 1982, The Combustion Institute, p. 1429.

18. Damle, A. S., Ensor, D. S., and Ranade, M. B. Aerosol Sci. Technol. 1982, 1, 119.

19. Quann, R., Neville, J. M., and Sarofim A. F. Combust. Sci. Technol. 1990, 74, 245.

20. Gladney, E. S., Small, J. A., Gordon, G. E., and Zoller, W. H. Atmos. Environ. 1976, 10, 1071 .

21. Linak, W. P., and Peterson, T. W. Twenty-First Symposium (International) on Combustion 1986. The Combustion Institute, p. 399.

22. Smith, A. H., and Goeden, H. M. Combust. Sci. Technol. 1990, 74, 51.

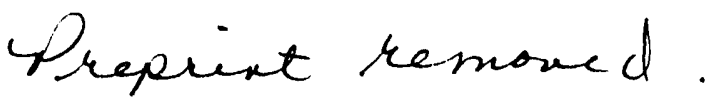



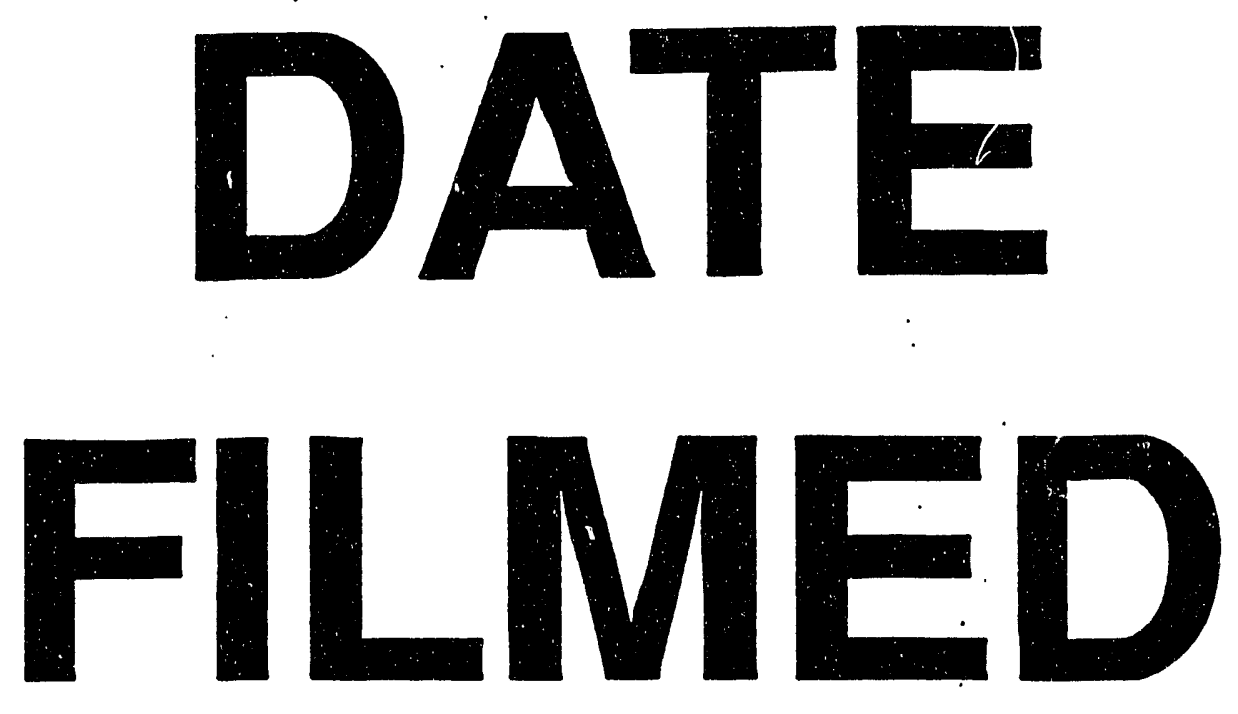

$10 / 20 / 93$
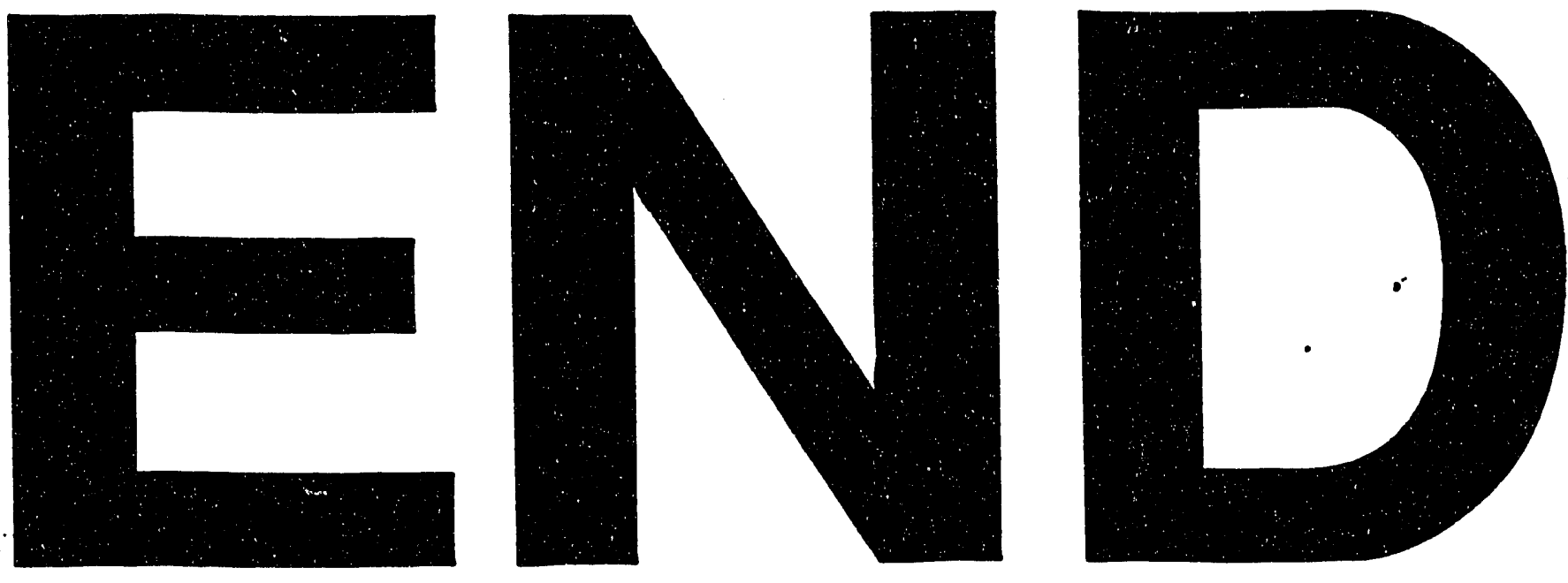
